This item was submitted to Loughborough's Research Repository by the author.

Items in Figshare are protected by copyright, with all rights reserved, unless otherwise indicated.

\title{
Efficient in-plane tire mode identification by radial-tangential eigenvector compounding
}

PLEASE CITE THE PUBLISHED VERSION

http://tiresciencetechnology.org/doi/full/10.2346/TIRE.15.430101

\section{PUBLISHER}

Published by The Tire Society and Allen Press Publishing Services. Copyright $@$ The Tire Society

\section{VERSION}

SMUR (Submitted Manuscript Under Review)

\section{PUBLISHER STATEMENT}

This work is made available according to the conditions of the Creative Commons Attribution-NonCommercialNoDerivatives 4.0 International (CC BY-NC-ND 4.0) licence. Full details of this licence are available at: https://creativecommons.org/licenses/by-nc-nd/4.0/

\section{LICENCE}

CC BY-NC-ND 4.0

\section{REPOSITORY RECORD}

Tsinias, Vasileios, and George Mavros. 2017. "Efficient In-plane Tire Mode Identification by Radial-tangential Eigenvector Compounding”. figshare. https://hdl.handle.net/2134/25373. 


\title{
Efficient in-Plane Tyre Mode Identification By Radial- Tangential Eigenvector Compounding
}

\author{
V. Tsinias* \\ v.tsinias@1boro.ac.uk \\ Department of Aeronautical and Automotive Engineering \\ Loughborough University \\ Epinal Way \\ Loughborough, Leicestershire, LE11 3TU \\ United Kingdom \\ G. Mavros \\ g.mavros@lboro.ac.uk \\ Department of Aeronautical and Automotive Engineering \\ Loughborough University \\ Epinal Way \\ Loughborough, Leicestershire, LE11 3TU \\ United Kingdom \\ Presented at the \\ 32nd Annual Meeting and Conference on Tire Science and Technology \\ Hilton Akron Fairlawn - Akron, $\mathrm{OH}$ \\ Tuesday, September 10, 2013 - Wednesday, September 11, 2013
}

*Presenter / Corresponding Author 


\section{Efficient in-Plane Tyre Mode Identification By Radial- Tangential Eigenvector Compounding}

\section{REFERENCE:}

ABSTRACT: Tyre modal testing is frequently used for validation of numerical tyre models and identification of structural tyre model parameters. Most studies deal with the case of a tyre fitted to a rigidly mounted rim and focus primarily on in-plane dynamic behaviour. Here, an identification method of in-plane tire dynamics is developed for the case of a free tyre-rim combination. This particular case is important when the aim is to construct a full tyre model from modal testing, capable of predicting ride and NVH phenomena involving the whole vehicle. Key attributes of the proposed approach include ease of implementation and efficient processing of measurements. For each type of excitation, i.e. radial and tangential, both radial and tangential responses are recorded. Compounding of the corresponding radial/tangential eigenvectors results in smooth mode shapes, which are found to agree with those published in other analytical and experimental studies.

\section{KEY WORDS:}




\section{Introduction}

Recent advances in automotive industry introduced the requirement for accurate and efficient transient tyre simulation, which imposes the need for tyre belt modelling. To this end, the usual method of attack has been to either model the tyre belt by interconnected finite elements, see [1] to [3], or via physical modelling, using springs, dampers and point masses, see [4] to [6]. Finite element tyre models tend to be accurate and reliable at the expense of high demands of computational power. Both categories require extensive identification of either tyre or material properties. An alternative approach is the prediction of tyre belt response as the superposition of the contribution of a finite number of flexible modes included in the frequency range of interest. This approach combines efficient simulation along with feasible identification procedures. The aim of the present work is to demonstrate these procedures and the resulting tyre modal properties.

\section{Experimental procedure}

One of the first critical parameters to be determined, with regards to the experimental layout, is the boundary condition of the wheel assembly. The broader scope of the present research, which is the development of a transient tyre model directly from experimentally identified modal parameters, leads to the adoption of the free tyre/rim boundary condition. The key point in understanding the selection of the particular boundary condition is the nature of the eigenvectors and the eigenvalues of any structure. In general, these quantities represent the solution of the eigenproblem formulated by the homogeneous system of differential equations of motion. Any constraint imposed on the rim would result in the omission of the respective rows and columns from this system of equations and, consequently, the derived modal quantities would not be characteristic of the tyre structure as they

would depend on the particular constraint type and geometry as well. Another problematic phenomenon associated with a rigidly mounted rim is the excitation of the attachment structure at natural frequencies close to the ones of the tyre belt. That case would jeopardise the experimental data and it would lead to unreliable eigenproperties. 
The circumference of the tyre is divided in 30 equally separated nodes, capable of moving in the two dimensional in-plane space. The radial and the tangential modes of the tyre belt are excited using an electromagnetic modal shaker by applying a force along the respective direction of the first node. The consequent response is obtained by placing the accelerometer at each node and by aligning its measuring axis with the radial or the tangential nodal direction. For each type of excitation (radial/tangential) both responses of every node are acquired.

The modal shaker is driven by an amplified white Gaussian noise signal. In order to minimize the effect of experimental errors and environmental noise on measured data, each test is repeated five times and the respective transfer functions are averaged. In total, for each one of the 2 mode categories, 60 transfer functions are obtained. The experimental layout is presented in figure 1 and the equipment used along with the experimental parameters may be found in table 1.

\section{Post processing}

Having obtained the necessary transfer functions, the next step is the identification of the modal properties associated with each mode. The approach is divided into two distinct procedures. Initially, the eigenvalues located in the frequency band of interest are identified using a MDOF rational fraction polynomial method followed by the identification of the residuals of each mode using an extended version of the general inverse analysis method to account for the non-proportional viscous damping witnessed in pneumatic tyres ${ }^{[7]}$.

Experimentally induced errors along with numerical inaccuracies led to several different residuals instead of a single exact value, affecting the form of the resulting frequency response function, see figure 2. In order to overcome this issue and define the most appropriate residue value amongst the calculated ones, an ad hoc selection criterion is implemented according to which each individual estimated frequency response function has a dominant effect on the - experimentally measured - total frequency response function within a frequency band close to the associated mode, see figure 3.

Since the driving point residue is available, the radial and tangential eigenvectors can be calculated. Due to the non-proportional viscous damping demonstrated in tyres and the associated mode 
complexity, the mode shapes derived from the calculated eigenvectors represent travelling waves along the tyre belt circumference. In order to depict these mode shapes and make a first visual check of the acquired data quality, one has to transform these complex modes into real ones, which are obtained by calculating the eigenvectors and the eigenvalues of an undamped system possessing the same mass and stiffness properties of the one examined above, see figures 4 to 7).

From the resulting real modes it is evident that, with the current experimental layout, and by comparing the quality of the purely radial modes (figure 4) to the quality of the purely tangential ones (figure 7), the former are more effectively excited than the latter. Nevertheless, the existence of numerically induced inaccuracy and experimental errors is apparent in both radial and tangential modes. In order to obtain a set of mode shapes capable of being used in a simulation environment, a digital filtering procedure must locate and indicate all those spatial frequencies around the circumference of the tyre which distort the fundamental waveform of each mode. The outcome of this attempt is presented in figures 8 to 13 and it is a set of smooth real mode shapes which, when coupled with the initial complex phase component, transforms to a spatially noise-free set of complex modes.

\section{Results}

The identified natural frequencies and damping ratios corresponding to radial modes are presented in table 2 . Note that each mode is associated with two eigenvalues, and hence with two natural frequencies and two damping ratios, due to the cross talking between radial and tangential modes meaning that radial excitation of the tyre will result in both radial and tangential responses. The same applies in the case of tangential excitation.

In theory, the natural frequency derived by the radial component of each mode should be identical to the one derived by the tangential component. In practice this is not the case but it is noteworthy that the maximum deviation between these two values is $2.58 \%$ (column "Delta" in table 2), proving the reliability of the experimental procedure and the quality of the identified data. Figures 8 and 9 demonstrate the mode shapes associated with the radial and 
the tangential response respectively and the compounded mode shapes are presented in Figure 10.

With regards to the tangential modes, the identified natural frequencies and damping ratios can be found in table 3. Once again, there is agreement between natural frequencies corresponding to radial and tangential response, as the maximum value of Delta function is 3\%. This particular table includes two additional tangential modes, compared to the radial ones, the existence of which is predicted by analytical tyre-related research ${ }^{[8]}$ but it has never been measured before (tangential modes 1 and 6). The explanation of this phenomenon is that due to the free-free boundary condition the respective radial modes have been transformed from flexible to rigid-body modes and as a result they have migrated to the rigid-body frequency band. Moreover, the tangential mode shapes corresponding to radial and tangential response can be found in figures 11 and 12 and the tangential mode shapes of the coupled response are presented in figure 13.

Examination of figures 10 and 13 reveals a series of repeated mode shapes, namely the first two radial modes, the first three tangential modes and the $5^{\text {th }}$ and the $6^{\text {th }}$ tangential modes as well. This phenomenon is not in accordance with published literature and, in order to understand its origin, the motion of the rim was acquired and analysed. For the case of radial excitation, this process revealed a resonance of the rim close to $132 \mathrm{~Hz}$, which is the natural frequency of the second repeated radial mode shape. Similarly, for the case of tangential excitation, the analysis of rim motion revealed three resonances close to the first, the second and the sixth tangential mode. What this observation means is that although the mode shapes are similar within each one of these three cases, they actually describe a different state of the tyre/rim assembly. In the first case consisting of two repeated radial modes, the first mode describes tyre belt deformation only, while the second radial mode includes the same tyre belt deformation along with motion or deformation of the rim. An identical interpretation of the 
rim modes applies to the remaining two cases, where the third and the fifth tangential mode demonstrate tyre belt deformation only. The remaining tangential modes - at $108 \mathrm{~Hz}, 116 \mathrm{~Hz}$ and at $196 \mathrm{~Hz}$ ) - include rim modes along with the deformation of the tyre belt. The determination of whether these rim modes are flexible or they describe rigid-body motion is beyond the scope of the present work.

\section{Conclusion}

An experimental procedure to obtain the eigenvalues and the eigenvectors of a pneumatic tyre has been designed. The tyre is freely suspended and divided into 30 nodes. The excitation signal is applied on the first node and the corresponding tyre response is acquired along the radial and the tangential direction of every node. Each test is performed 5 times in order to eliminate noise and the influent of experimental errors on the acquired data.

Having obtained the excitation and the response in the time domain, they are transformed to the frequency domain and the resulting frequency response functions are calculated. Using a typical FRP algorithm, the eigenvalues of the system have been calculated. In order to accommodate for out of band modes, the general inverse analysis method was adopted and modified to allow for non-proportional viscous damping witnessed in tyres.

The identification of the system eigenvalues led to the natural frequency and the damping ratio of each mode. As expected from previously published works, there is agreement in terms of natural frequencies for the same mode along different directions and between radial and tangential modes. One interesting finding is the observation of two additional tangential modes, which is predicted by previous analytical work but it has never been experimentally verified before.

The identified complex modes of the structure enabled the calculation of the respected real ones. The quality of the corresponding mode shapes, especially in the cases which involved either tangential excitation or tangential response, led to the requirement of filtering out all spatial frequencies but the 
one forming the mode shape along the tyre circumference. Without losing any piece of fundamental information, the mode shape quality is significantly enhanced. 


\section{References}

[1] P. Kindt, P. Sas and W. Desmet, Development and validation of a three-dimensional ring-based structural tyre model, Journal of Sound and Vibration, v. 326, p 852-869, 2009

[2] H. Sugiyama, Y. Suda, Non-linear elastic ring tyre model using the absolute nodal coordinate formulation, Proceedings of the Institution of Mechanical Engineers, Part K: Journal of Multibody dynamics, v. 223(3), pp. 211-219, 2009

[3] C. Oertel and A. Fandre, Ride comfort situations and steps towards life time calculations: RMOD-K and ADAMS, International ADAMS Users' Conference, Berlin, 1999

[4] M. Gipser, FTire: a physically based application-oriented tyre model for use with detailed MBS and finite-element suspension models, Vehicle System Dynamics, vol. 43, n. 1, p. 76-91, 2005

[5] M. Gipser, FTire - the tire simulation model for all application related to vehicle dynamics, Vehicle System Dynamics, vol. 45, n. S1, p. 139-151, 2007

[6] A. Gallrein, M. Backer, CDTire: a tire model for comfort and durability applications, Vehicle System Dynamics, v. 45(s1), pp. 69-77, 2007

[7] A. A. Popov, Z Geng, "Modelling of vibration damping in pneumatic tyres", Vehicle System Dynamics, v. 3 (s1), pp. 145-155, 2005.

[8] A. Tsotras, "On the interaction between modal behaviour and contact force development of a pneumatic tyre", $\mathrm{PhD}$ Thesis, Department of Aeronautical and Automotive Engineering, Loughborough University, 2009. 


\section{List of Tables}

TABLE 1 - Experimental equipment and parameters

TABLE 2 - Identified natural frequencies and damping ratios of radial modes

TABLE 3 - Identified natural frequencies and damping ratios of tangential modes 
TABLE 1 - Experimental equipment and parameters

\begin{tabular}{|l|c|}
\hline Tyre & Continental 195/50 R15 \\
\hline Sampling Rate & 20000 [Hz] \\
\hline Frequency Band & Brüel \& Kjær - Type 8230 \\
\hline Force Transducer & Brüel \& Kjær - Type 4332 \\
\hline Accelerometer & Brüel \& Kjær - Nexus \\
\hline Charge Amplifier & Type 2691-A-0S2 \\
\hline Modal Shaker & Brüel \& Kjær - LDS V201 \\
\hline Acquisition Card & NI PCIe-6259 \\
\hline
\end{tabular}

TABLE 2 - Identified natural frequencies and damping ratios of radial modes

\begin{tabular}{|c|c|c|c|c|c|}
\hline Mode & $\begin{array}{c}\text { Nat. Freq. }[\mathrm{Hz}] \\
\text { (radial resp.) }\end{array}$ & $\begin{array}{l}\text { Nat Freq. [Hz] } \\
\text { (tangential resp.) }\end{array}$ & $\begin{array}{c}\text { Delta }[\%] \\
\Delta_{\omega}=\frac{\left|\omega_{r}-\omega_{t}\right|}{\left(\omega_{r}+\omega_{t}\right) / 2}\end{array}$ & $\begin{array}{c}\text { Damp. Ratio [\%] } \\
\text { (radial resp.) }\end{array}$ & $\begin{array}{l}\text { Damp. Ratio [\%] } \\
\text { (tangential resp.) }\end{array}$ \\
\hline 1 & 115 & 118 & 2.58 & 3.63 & 3.81 \\
\hline 2 & 131 & 133 & 1.51 & 6.19 & 5.91 \\
\hline 3 & 155 & 153 & 1.30 & 6.61 & 6.28 \\
\hline 4 & 180 & 180 & 0.00 & 5.93 & 6.26 \\
\hline 5 & 208 & 207 & 0.48 & 5.48 & 6.05 \\
\hline 6 & 242 & 241 & 0.41 & 3.28 & 2.35 \\
\hline 7 & 275 & 276 & 0.36 & 5.81 & 5.91 \\
\hline 8 & 320 & 321 & 0.31 & 5.61 & 6.71 \\
\hline 9 & 371 & 370 & 0.27 & 6.87 & 6.87 \\
\hline 10 & 413 & 420 & 1.68 & 7.05 & 5.77 \\
\hline
\end{tabular}


TABLE 3 - Identified natural frequencies and damping ratios of tangential modes

\begin{tabular}{|c|c|c|c|c|c|}
\hline Mode & $\begin{array}{c}\text { Nat. Freq. [Hz] } \\
\text { (radial resp.) }\end{array}$ & $\begin{array}{c}\text { Nat Freq. }[\mathrm{Hz}] \\
\text { (tangential resp.) }\end{array}$ & $\begin{array}{c}\text { Delta }[\%] \\
\Delta_{\omega}=\frac{\left|\omega_{r}-\omega_{t}\right|}{\left(\omega_{r}+\omega_{t}\right) / 2}\end{array}$ & $\begin{array}{c}\text { Damp. Ratio [\%] } \\
\text { (radial resp.) }\end{array}$ & $\begin{array}{l}\text { Damp. Ratio [\%] } \\
\text { (tangential resp.) }\end{array}$ \\
\hline 1 & 108 & 106 & 1.87 & 4.14 & 3.54 \\
\hline 2 & 116 & 117 & 0.86 & 4.22 & 4.09 \\
\hline 3 & 134 & 135 & 0.74 & 6.50 & 6.63 \\
\hline 4 & 153 & 150 & 1.98 & 6.06 & 6.25 \\
\hline 5 & 177 & 177 & 0.00 & 5.28 & 6.48 \\
\hline 6 & 196 & 198 & 1.02 & 4.23 & 8.18 \\
\hline 7 & 207 & 208 & 0.48 & 4.64 & 5.26 \\
\hline 8 & 236 & 238 & 0.84 & 4.47 & 4.24 \\
\hline 9 & 273 & 272 & 0.37 & 4.51 & 4.56 \\
\hline 10 & 318 & 318 & 0.00 & 4.74 & 4.58 \\
\hline 11 & 375 & 375 & 0.00 & 5.95 & 5.18 \\
\hline 12 & 404 & 403 & 0.25 & 4.06 & 4.59 \\
\hline 13 & 473 & 459 & 3.00 & 1.64 & 2.20 \\
\hline
\end{tabular}




\section{List of Figure Captions}

FIG 1 - Experimental layout

FIG 2 - Calculated frequency response functions corresponding to a range of calculated residue values

FIG 3 - Selection of the residue value generating the FRF closer to the experimentally obtained mode

FIG 4 - Real mode shapes (radial excitation, radial response)

FIG 5 - Real mode shapes (radial excitation, tangential response)

FIG 6 - Real mode shapes (tangential excitation, radial response)

FIG 7 - Real mode shapes (tangential excitation, tangential response)

FIG 8 - Noise-free real mode shapes (radial excitation, radial response)

FIG 9 - Noise-free real mode shapes (radial excitation, tangential response)

FIG 10 - Noise-free real radial mode shapes

FIG 11 - Noise-free real mode shapes (tangential excitation, radial response)

FIG 12 - Noise-free real mode shapes (tangential excitation, tangential response)

FIG 13 - Noise-free real tangential mode shapes 


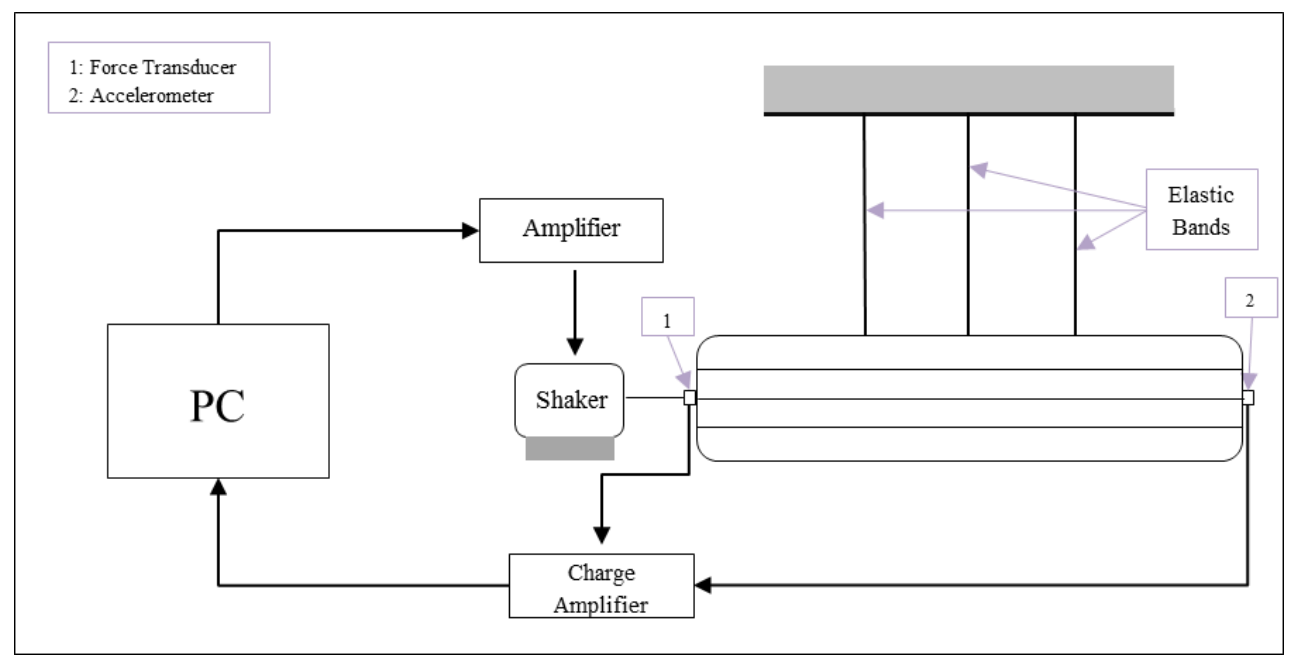

FIG. 1 - Experimental layout

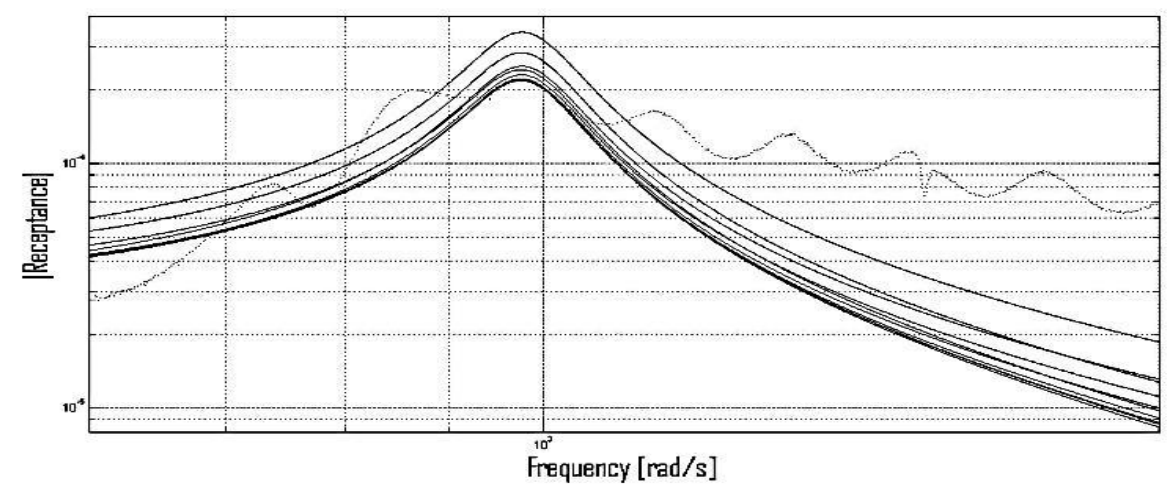

FIG. 2 - Calculated frequency response functions corresponding to a range of calculated residue values

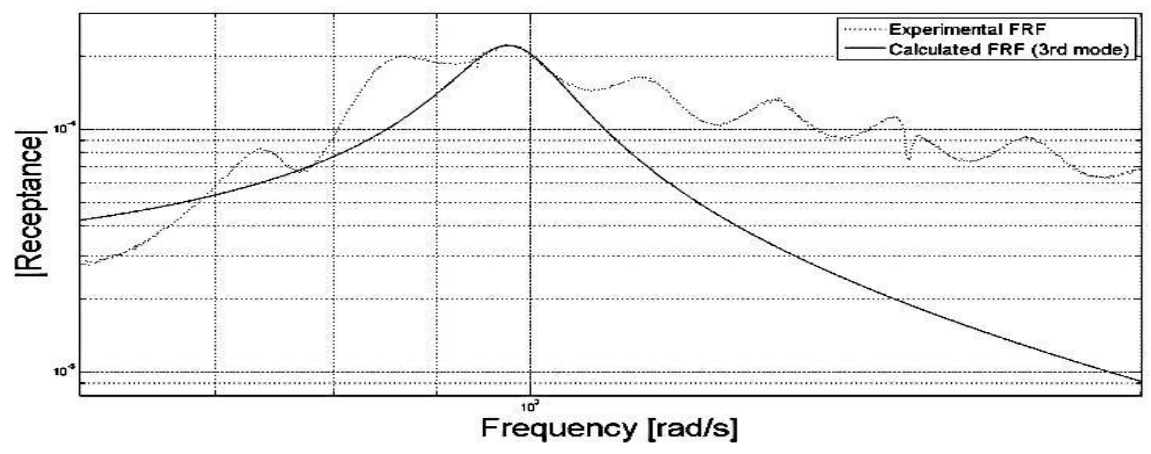

FIG. 3 - Selection of the residue value generating the FRF closer to the experimentally obtained mode 

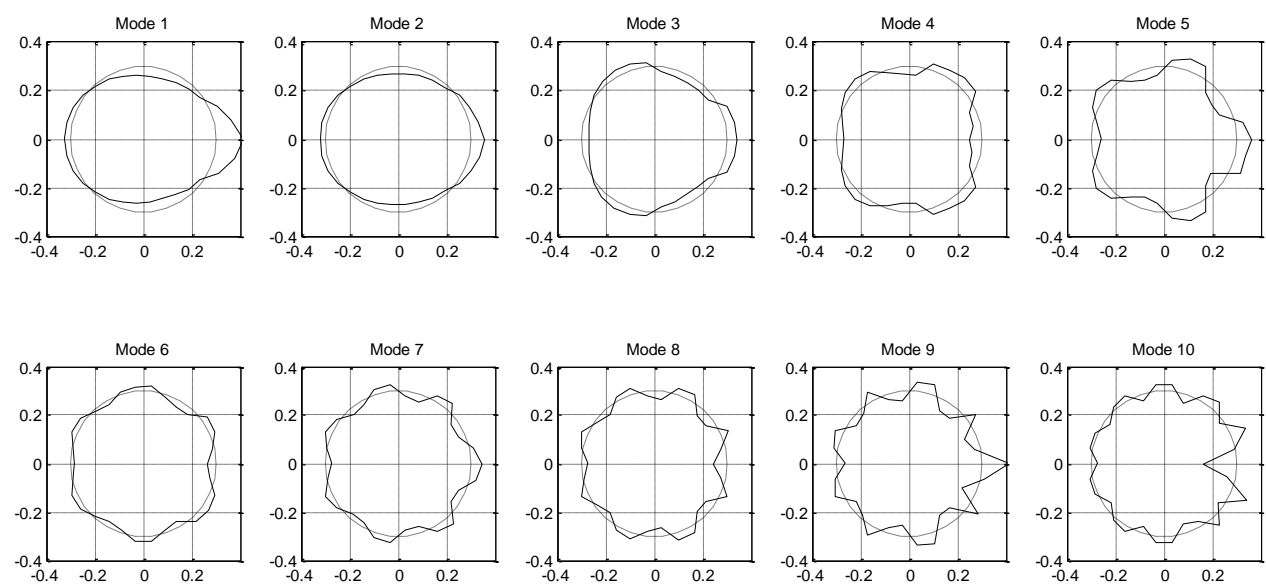

FIG. 4 - Real mode shapes (radial excitation, radial response)
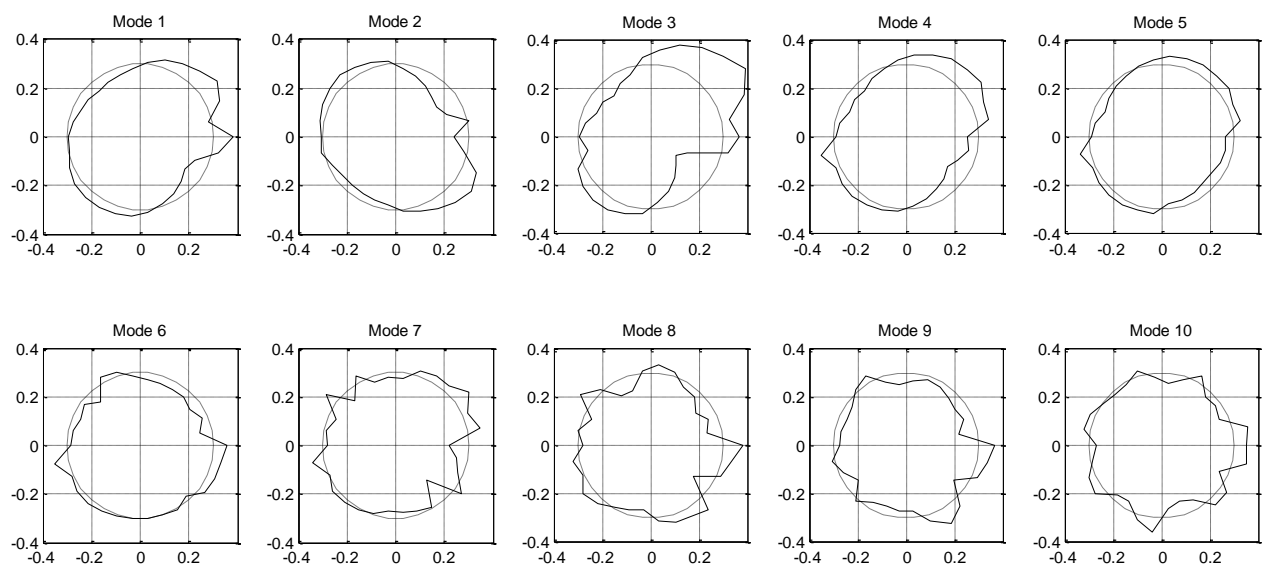

FIG. 5 - Real mode shapes (radial excitation, tangential response) ${ }^{a}$ 

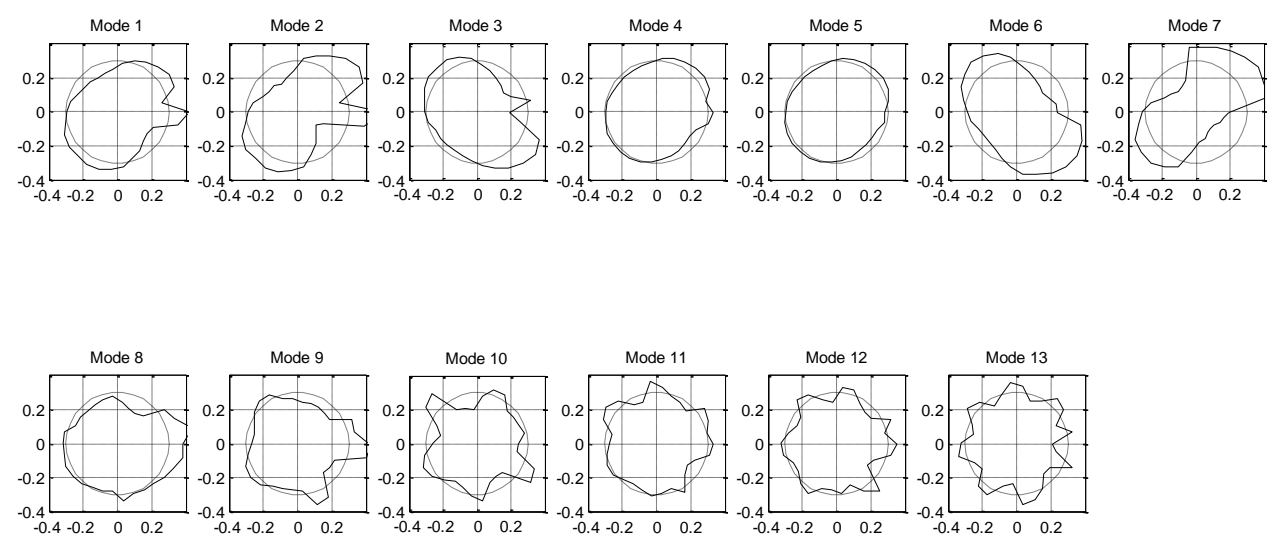

FIG. 6 - Real mode shapes (tangential excitation, radial response)
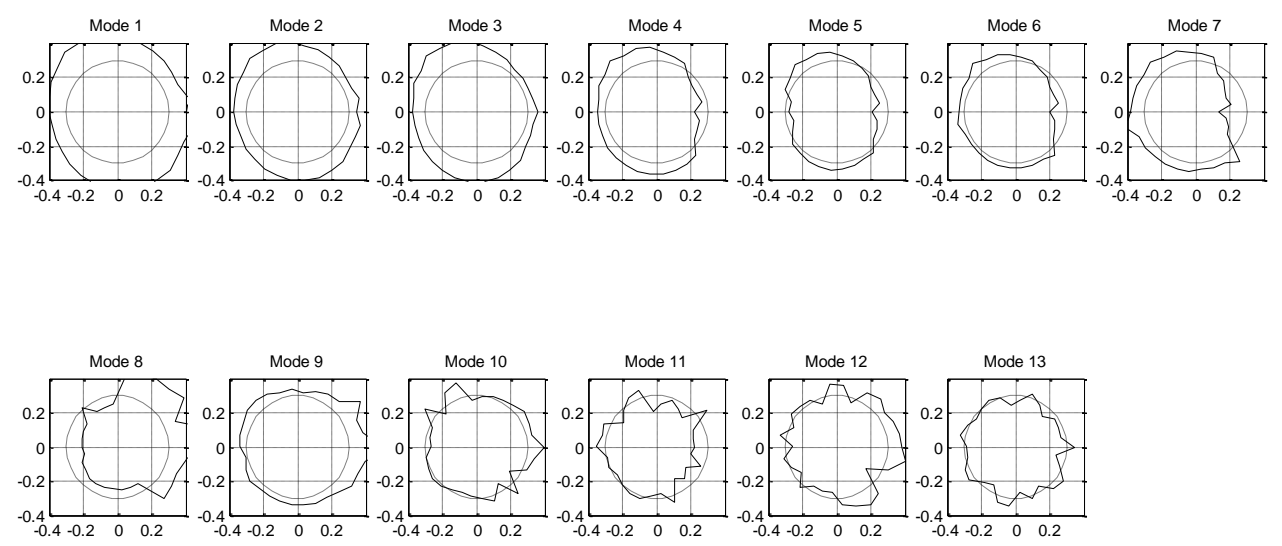

FIG. 7 - Real mode shapes (tangential excitation, tangential response) ${ }^{a}$ 

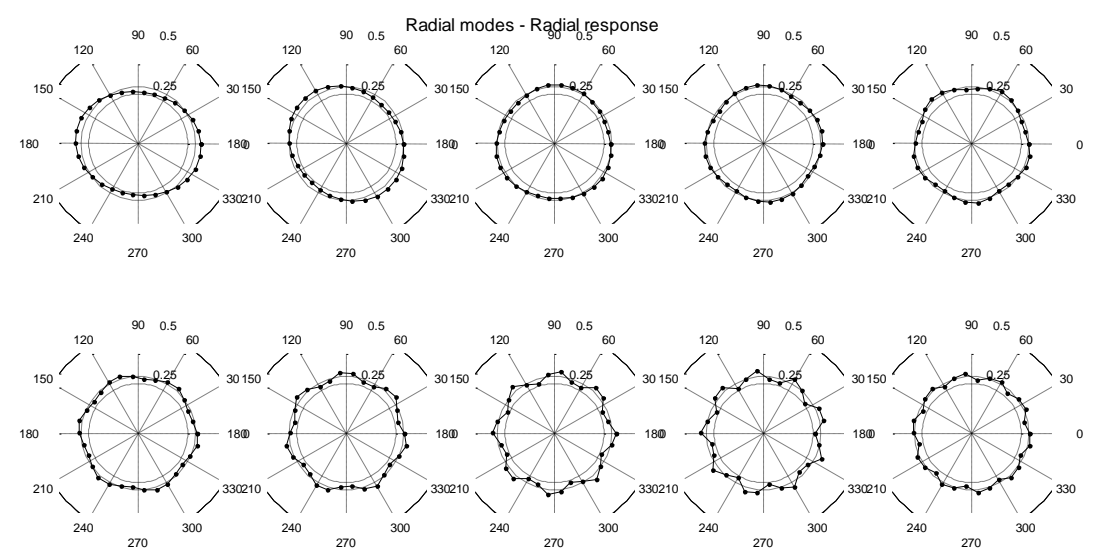

FIG. 8 - Noise-free real mode shapes (radial excitation, radial response)
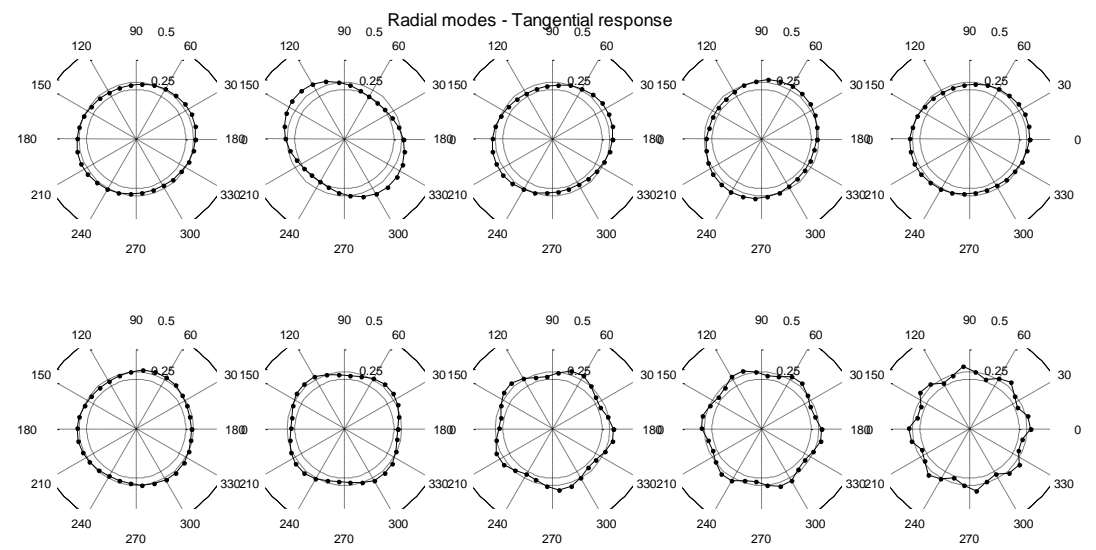

FIG. 9 - Noise-free real mode shapes (radial excitation, tangential response) ${ }^{a}$ 
Radial Modes
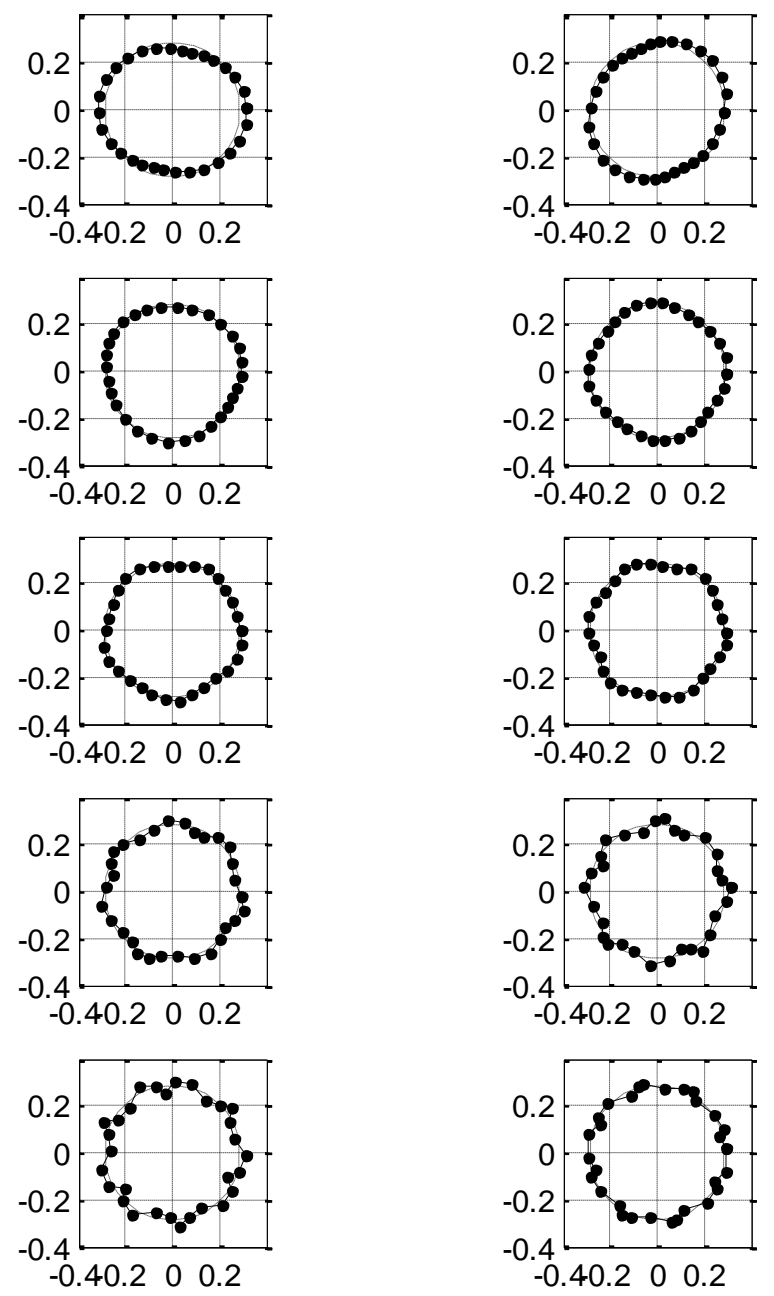

FIG. 10 - Noise-free real radial mode shapes 

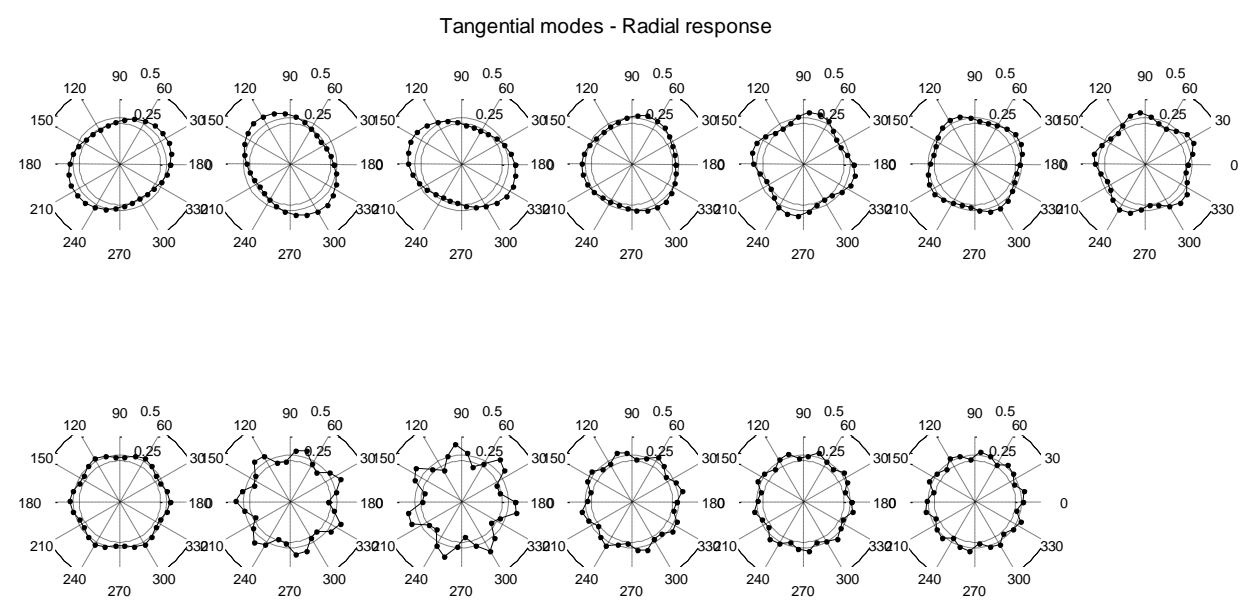

FIG. 11 - Noise-free real mode shapes (tangential excitation, radial response)

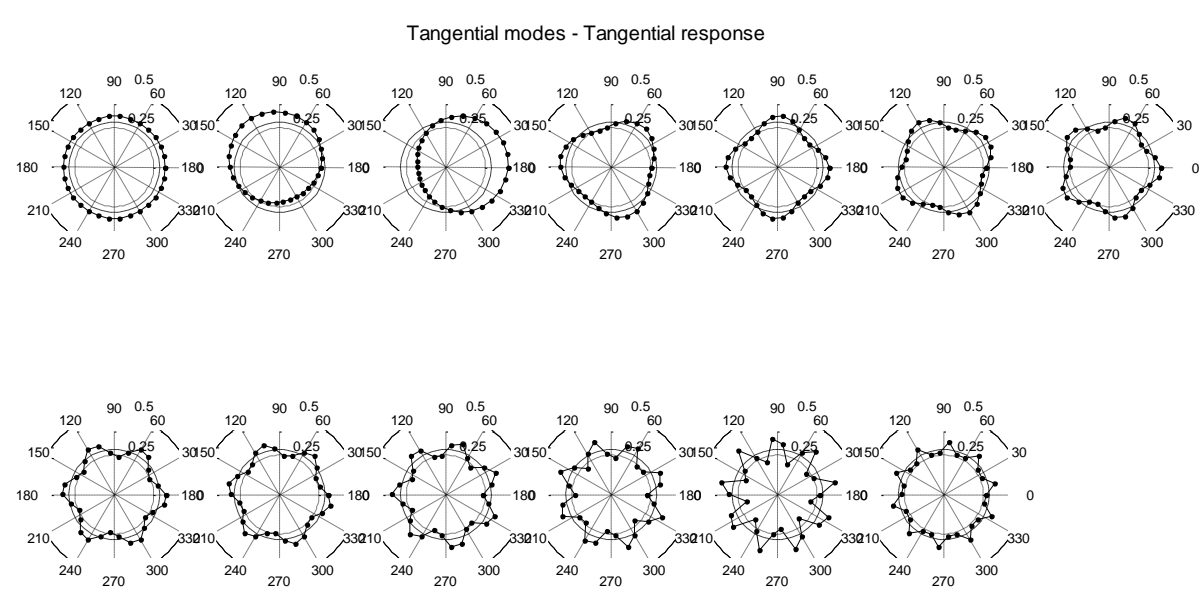

FIG. 12 - Noise-free real mode shapes (tangential excitation, tangential response) ${ }^{a}$ 


\section{Tangential Modes}

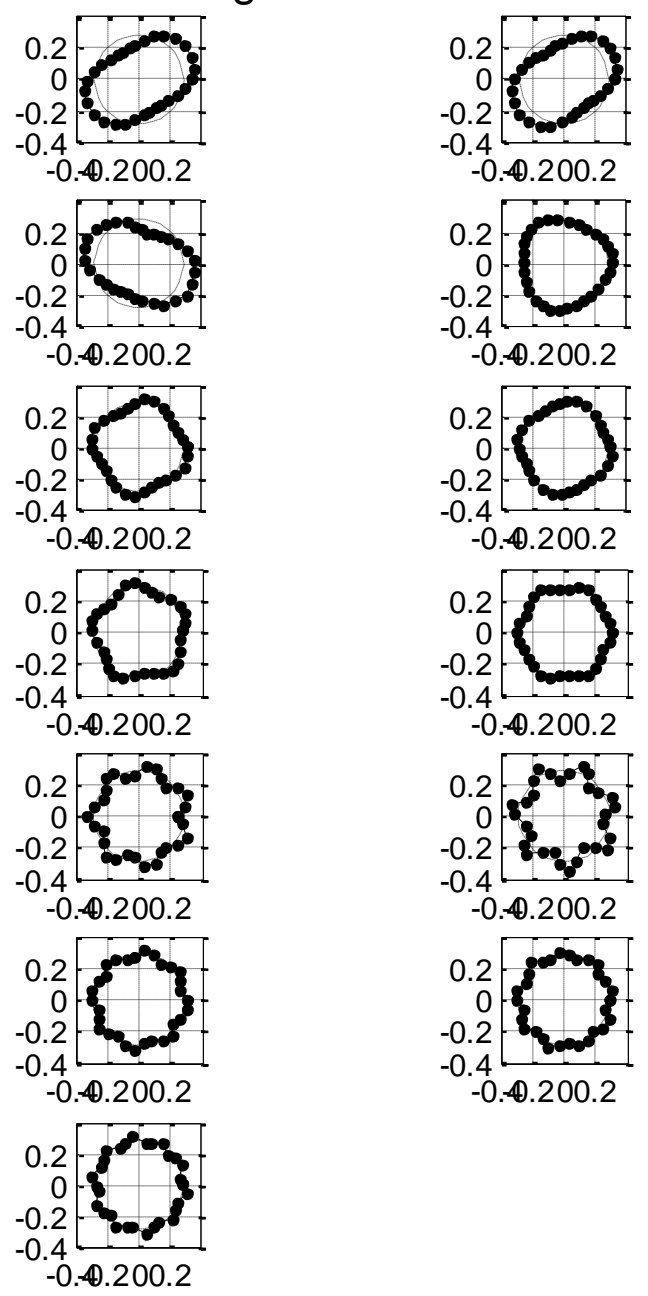

FIG. 13 - Noise-free real tangential mode shapes

${ }^{\text {a }}$ For clarity, tangential response is presented as radial with clockwise tangential deformation being replaced by a radially outwards one and vice versa. 